\title{
- princípio do mal na obra de Gabriel Garavello
}

Rodrigo Montandon Born

Tatiana Lee Marques

Há no trabalho de Gabriel Garavello, um limite tênue entre transparência e opacidade, dois conceitos opostos propostos por Baudrillard, que tornam o trabalho do artista enigmático e envolvente.

Em sua pincelada, que toma forma no excessivo uso e na densidade de tinta, contempla-se um véu sutil de volumes, cores e texturas que a sua própria maneira apresenta uma opacidade velada, comum em muitos trabalhos de artistas consagrados (tais como Rothko, Turner ou mesmo El Greco), onde a atmosfera parece revelar-se aos poucos, em consequência de um olhar atento do espectador. É como esperar que a imagem surja na fotografia pelo processo de emulsão, os artistas que sabem trabalhar com este tipo de artifício, proporcionam ao espectador um jogo lento de revelações, que não entrega a imagem imediatamente.

Porém, Garavello usa com precisão o artifício da opacidade da imagem para prender o espectador e ir um passo adiante. O espectador fica diante da obra que não revela a si mesma em uma primeira instância, ele está no escuro sem contemplar precisamente o que está por vir. Neste momento, ele consegue apenas contemplar as texturas, causadas por arranhões e sobreposições das massas de tintas, que por sua natureza carregada, anunciam uma atmosfera tensa que começa a se revelar parcialmente. 


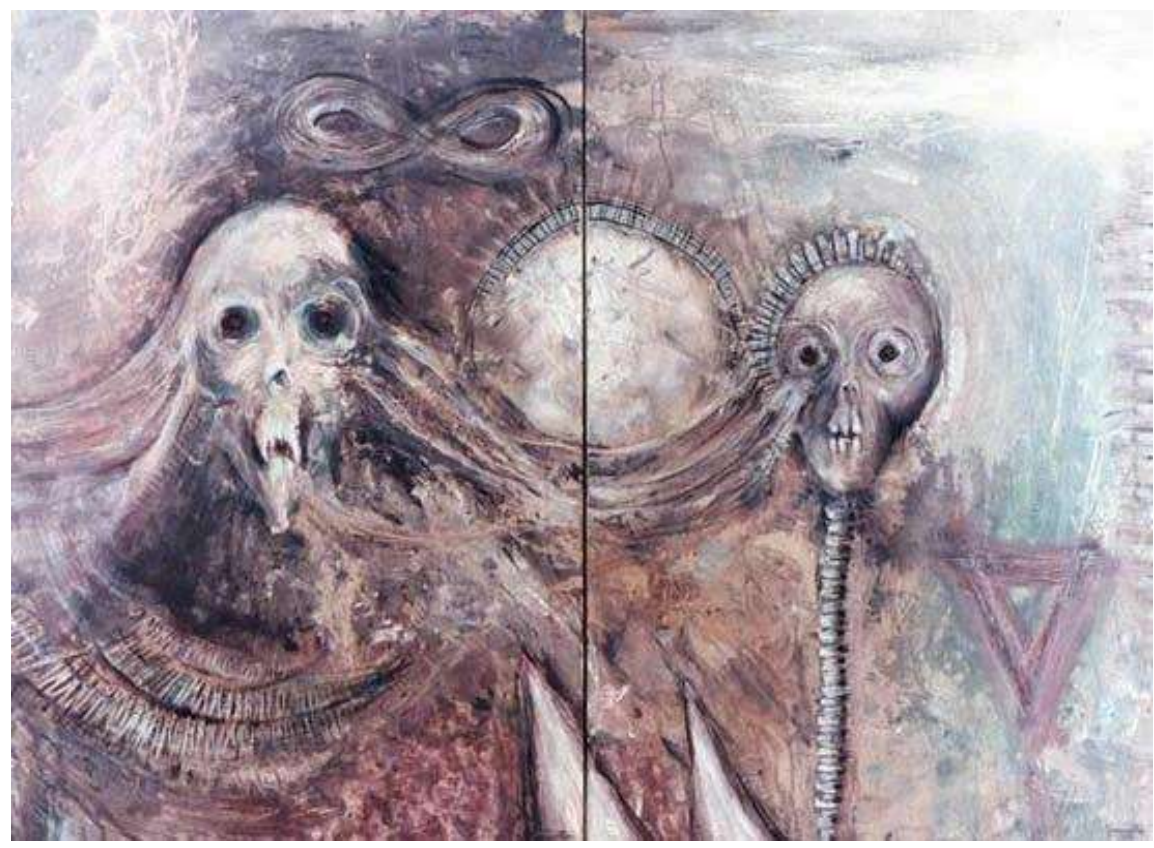

Figura 1. Pintura sem título, acrilico sobre tela, diptico. Fonte: Acervo do artista.

Em um segundo momento, como pode-se observar na Figura 1, a imagem revela figuras assustadoras, que parecem imobilizar aquele que as olha, e suga parte do calor que a ele pertencia. São pinturas vampíricas, são blocos de afetos e perceptos trazidos pelo artista, que provavelmente são gestados a partir de uma vasta coleção de filmes de terror que pertencem a Garavello.

Nas imagens que se revelam, temos um vislumbre do mal, e tal como é a transparência do mal para Baudrillard, temos um principio do mal que "não é moral; é um princípio de desequilíbrio e de vertigem, princípio de complexidade e de estranheza, de sedução, de incompatibilidade".

Para o autor, o princípio do mal "não é um princípio de morte, mas é o princípio vital de desligação". Temos nas printuras de Garavello todas estas sensações: estranheza, sedução, desequilíbrio e vertigem.

A estranheza surge já no primeiro momento, através uma pincelada carregada, texturas que parecem com metal oxidado, sujeira ou mesmo uma neblina, é a estranheza que gera a atmosfera fria e carregada citada anteriormente. Imagem, cores e texturas, parecem ocultar sutilmente o conteúdo imagético da obra. Quando oculta o conteúdo do trabalho, o artista parece seduzir seu espectador: 




Aproxime-se - diz a pintura - você quer saber o que eu escondo em mim. Para Baudrillard:

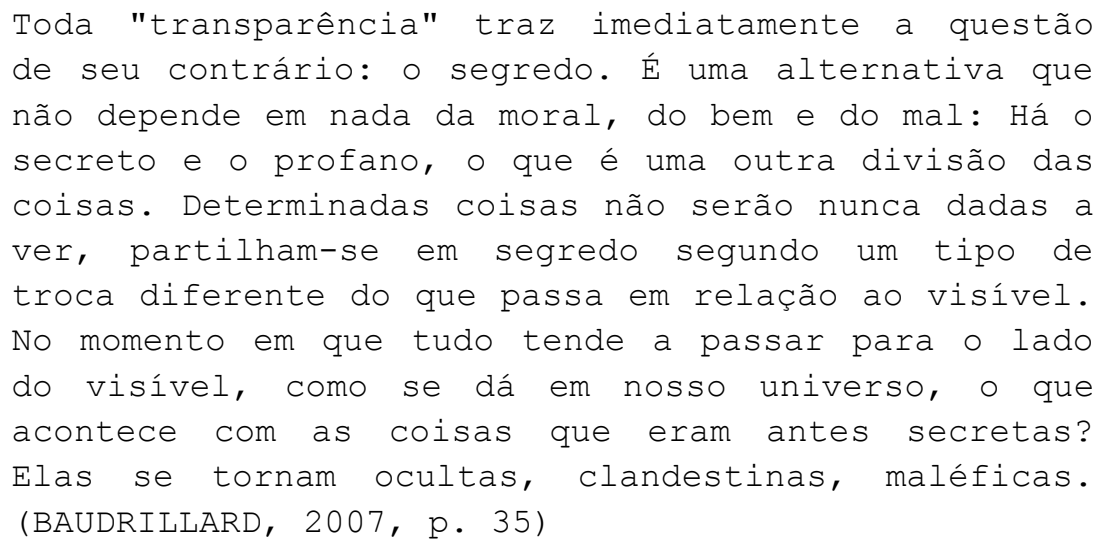

O desequilíbrio e a vertigem, como uma consequência do primeiro, surgem exatamente como nos filmes de terror. Uma revelação assustadoramente imediata que causa total vertigem no espectador. O seu medo não surge da morte, que parece eminente, algo que não pode optar ou controlar, mas no princípio de desligação daquilo que a ele pertence.



Figura 2. Pintura sem título, acrílico sobre tela, díptico. Fonte: Acervo do artista.

A pintura de Garavello, como propõe Didi-Huberman, observa aquele que a olha, e como propõe o mesmo autor, há um equivoco recorrente, referente à pintura, a de que o quadro é "vivo".

Talvez seja um dos grandes princípios retóricos do movere, da comoção pictórica. Igualmente um dos mais comuns. Mas ele somente mostra toda a sua 


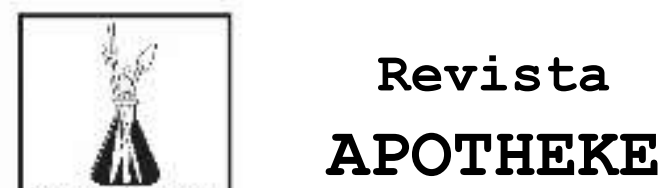

APOTHEKE

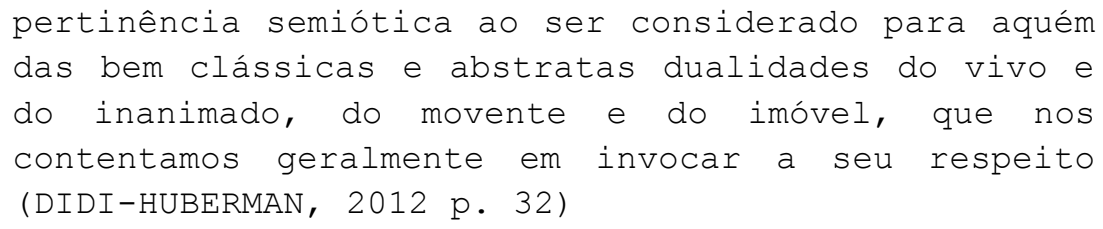

Os quadros de Garavello parecem querer tirar do espectador aquilo que elas não possuem, e neste processo, onde o espectador se sente imobilizado diante da obra, elas adquirem a sua própria condição de pinturas encarnadas.

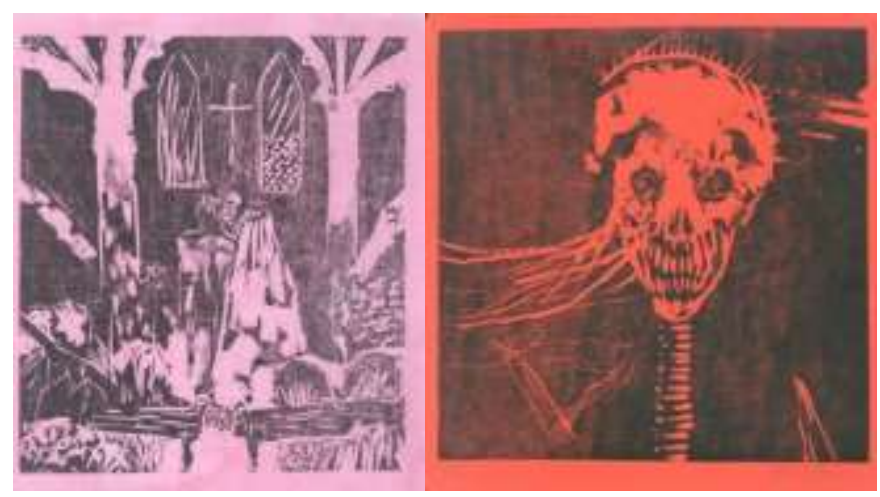

Figuras 3 e 4. Gravuras sem título. Fonte: Acervo do artista.



Figura 5. Pintura sem título, acrílico sobre tela. Fonte: Acervo do artista.

\section{Referências}

DIDI-HUBERMAN, Georges. A pintura encarnada. Tradução de Osvaldo Fontes. Filho. São Paulo: Escuta, 2012.

BAUDRILLARD, JEAN. Senhas. Tradução de Maria Helena Kuhner. - 2 a edição - Rio de Janeiro: DIFEL, 2007 